\title{
Obsevisto
}

ISSN n² 2447-4266

Vol. 1, n 2, Setembro-dezembro. 2015

DOI: http://dx.doi.org/10.20873/uft.2447-4266.2015v1n2p174

\section{Criatividade ao cubo: proposta de um modelo teórico para o ensino e aprendizagem da criação publicitária}

Creativity to the cube: proposal for a theoretical model to teaching and learning of the creative process in advertising

Creatividad al cubo: propuesta de un modelo teórico para la enseñanza y el aprendizaje de la creación publicitaria.

Ricardo Zagallo Camargo ${ }^{1,2,3}$

\section{RESUMO}

Ensaio que propõe um modelo para contribuir com o ensino e aprendizagem da criação publicitária, em especial em cursos de graduação de publicidade e propaganda. O texto tem como base um levantamento bibliográfico e documental e a experiência do autor como professor universitário na Universidade de Mogi das Cruzes e na Escola de Comunicação e Artes da USP, entre 1999 e 2006. A partir do entendimento de criatividade como um ato social, com compromissos, responsabilidades e vínculo com uma determinada materialidade (OSTROWER, 1987), propõe um modelo com três dimensões: repertório operacionalizável; capacidade de combinação; e responsabilidades múltiplas (sociais, culturais e criativas, entre outras).

\footnotetext{
1 Doutor em Ciências da Comunicação pela ECA-USP. Diretor do Centro de Altos Estudos da ESPM. Email: zagallo@espm.br.

2 Endereço de contato do autor (por correio): Escola Superior de Propaganda e Marketing (ESPM). Centro de Altos Estudos. Rua Dr. Álvaro Alvim, 123 - Vila Mariana, São Paulo - SP. Brasil. CEP: 04018010.

${ }^{3}$ Versão revisada de texto apresentado no DT 6 - GP Comunicação e Educação, XIV Encontro dos Grupos de Pesquisas em Comunicação, evento componente do XXXVII Congresso Brasileiro de Ciências da Comunicação.
} 


\section{Observisto}

ISSN n² 2447-4266

Vol. 1, n² 2, Setembro-dezembro. 2015

DOI: http://dx.doi.org/10.20873/uft.2447-4266.2015v1n2p174

Dimensões que se contempladas, permitiriam atingir um nível de criatividade "elevado ao cubo".

PALAVRAS-CHAVE: Criatividade; Criação publicitária; Educação superior; Ensino e aprendizagem; Responsabilidade social.

\section{ABSTRACT}

This essay proposes a preliminary model to improve the teaching and learning of the creative process, particularly in the context of undergraduate courses on advertising. The proposal was based in a bibliographic review, documental search, and in the author's experience as university professor between 1999 and 2006 at the University of Mogi das Cruzes (UMC) and University of São Paulo (ECA-USP). The theoretical basis refers to the comprehension of creativity as a social act, its commitments and responsibilities. An act that is intrinsically linked to a specific materiality (OSTROWER, 1987). From these theoretical and methodological basis, we propose a model that has three dimensions: operational repertory (a repertory ready for use); combination skills (especially to make unexpected connections); and the diverse professional responsibilities (social, environmental, cultural, creative responsibilities, amongst others). In case these dimensions are really taken as boosting the creative process, it could "creativity to the cube".

KEYWORDS: creativity; creative process; advertising; teaching and learning; responsibilities

\section{RESUMEN}

Ensayo que propone un modelo preliminar para mejorar la enseñanza y el aprendizaje del proceso creativo, en particular en el contexto de los cursos de licenciatura en materia de publicidad. La propuesta se basa en una revisión bibliográfica, la búsqueda documental y en la experiencia del autor como profesor universitario, entre 1999 y 2006 en la Universidad de Mogi das Cruzes (UMC) y la Universidad de São Paulo (ECA-USP). La base teórica se refiere a la comprensión de la creatividad como un acto social, sus compromisos y responsabilidades. Un acto que está intrínsecamente vinculado a una materialidad específica (Ostrower, 1987). A partir de estas bases teóricas y metodológicas, proponemos un modelo que tiene 


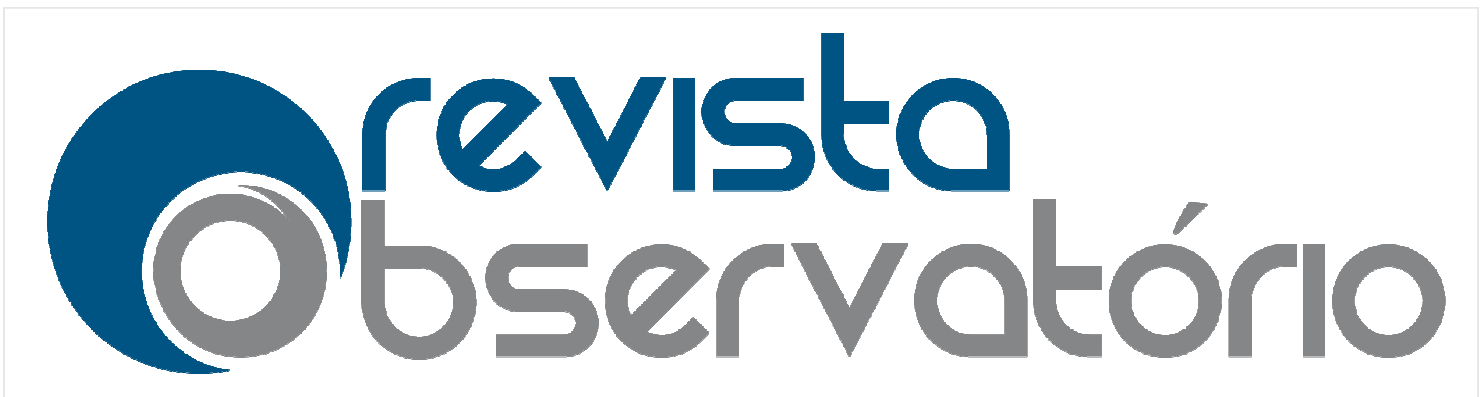

ISSN n² 2447-4266

Vol. 1, n 2, Setembro-dezembro. 2015

DOI: http://dx.doi.org/10.20873/uft.2447-4266.2015v1n2p174

tres dimensiones: repertorio operativo (un repertorio listo para su uso); habilidades de combinación (especialmente para hacer conexiones inesperadas); y las diversas responsabilidades profesionales (responsabilidades creativas, sociales, ambientales, culturales, entre otros). Dimensiones que se contemplan, alcanzarían un nivel de creatividad "al cubo".

PALABRAS CLAVE: la creatividad; proceso creativo; publicidad; enseñanza y el aprendizaje; responsabilidades

Recebido em: 21.09.2015. Aceito em: 20.11.2015. Publicado em 08.12.2015. 


\section{Obevisto \\ ISSN n² 2447-4266 \\ Vol. 1, n², Setembro-dezembro. 2015 \\ DOI: http://dx.doi.org/10.20873/uft.2447-4266.2015v1n2p174}

\section{Considerações iniciais e justificativas}

Este artigo constitui um desdobramento de trabalhos anteriores apresentados nos Congressos da Intercom nos anos de 2013 e 2014, que permitiram, a partir da interlocução com os colegas do campo, o detalhamento e ampliação de um modelo teórico que contribua para a reflexão e prática do ensino e aprendizagem da criação publicitária, em especial nos cursos de Comunicação Social, com habilitação em Publicidade e Propaganda. Para chegar a essa proposta partimos de reflexões conceituais, levantamento da literatura, e da experiência do autor como professor de criação publicitária (e disciplinas correlatas, como Redação publicitária, Comunicação responsável, Projeto Experimental, entre outras) na Universidade de Mogi das Cruzes e na Escola de Comunicação e Artes da USP, no período entre 1999 e 2006. Também contribuiu para a elaboração do modelo a participação do autor na equipe que conduziu o desenvolvimento de Indicadores de Sustentabilidade para Agências de Comunicação da ABAP entre 2010 e 2012.

A proposta de um modelo teórico com elementos que articulem demandas sociais e mercadológicas no sentido de contribuir para uma comunicação que seja ao mesmo tempo criativa e responsável possui pelo menos três justificativas.

Primeiramente a proposta justifica-se pelo fato da disciplina de criação publicitária ser, como observa Hansen (2011), atravessada por um discurso que emana do mercado para legitimar as atividades que ocorrem na universidade. Esse autor levanta fortes indícios, a partir de procedimentos empíricos (instalação de uma câmera nas salas e posterior tratamento do material coletado com instrumental de análise de discurso), de que é especialmente forte a presença do discurso do mercado em sala de aula, numa tentativa dos professores de, a partir de um estudante imaginado, legitimar as aulas por meio de constantes referências a atuações profissionais bem sucedidas. Nesse sentido é comum, entre alunos de graduação, perguntar se o professor trabalha (ou trabalhou) no mercado publicitário (leia-se em grandes agências ou empresas de comunicação) ou se ele "só" dá aulas. 


\section{Obevisto}

ISSN n² 2447-4266

Vol. 1, n 2, Setembro-dezembro. 2015

DOI: http://dx.doi.org/10.20873/uft.2447-4266.2015v1n2p174

Uma situação que estimula as tentativas de replicar as condições mercadológicas e a valorização dos profissionais "de mercado", seja pela contratação desses profissionais como professores, seja pela participação deles como convidados ao longo dos cursos. Tentativas essas que contribuem para converter as disciplinas ligadas à criação publicitária e as agências experimentais das universidades em espaços de reprodução (em geral cópias pálidas do que acontece no mundo "real"). Tal procedimento, embora "funcione", no sentido de satisfazer a demanda dos estudantes por atividades práticas e por proximidade com o mercado de trabalho, reforça uma posição de inferioridade da universidade em relação ao mercado de trabalho e desvaloriza o espaço educacional, com risco real de abrir mão das tarefas de ensino e aprendizagem, reduzindo a sala de aula a um espaço de reprodução e não espaço de experimentação, com potencial para gerar ideias e transformar a atuação profissional (HANSEN, 2013: p.469). Não queremos dizer, com isso, que a universidade deva desconsiderar a prática mercadológica, mas sim partir dessa prática para a realização do potencial de experimentação do ambiente educacional. Em outras palavras, ter as práticas de mercado como primeira etapa para a criação de um espaço de aprendizagem capaz de atrair os olhares do mercado pelo que traz de criativo e inovador.

A segunda justificativa recai no fato de que serão cada vez mais intensas as demandas sociais por uma comunicação mais responsável, capaz de contribuir para a construção de valores sociais, combater estigmas e preconceitos, além de valorizar diferentes grupos socioculturais. Demandas que não partem apenas da sociedade civil, mas também dos grandes anunciantes, como a Nestlé, que aderindo ao EU Pledge on Advertising to Children, coalização de fabricantes internacionais de alimentos e bebidas (com a presença de Danone, Coca-Cola e Unilever, entre outras) optou, desde 2009, por não veicular anúncios dirigidos a crianças menores de seis anos e veicular apenas produtos com perfil nutricional que ajudem a criança a ter uma dieta balanceada para o público de 6 a 12 anos. Uma discussão, que envolve 


\section{Obevisto}

ISSN n² 2447-4266

Vol. 1, n 2, Setembro-dezembro. 2015

DOI: http://dx.doi.org/10.20873/uft.2447-4266.2015v1n2p174

amplos setores da sociedade, e demanda dos publicitários e de suas entidades um trabalho consistente de conscientização sobre sua atividade para lidar com as críticas cada vez mais intensas às atividades ligadas a publicidade e ao consumo.

Em terceiro lugar, a proposta justifica-se pela observação das mudanças constantes pelas quais passa o mercado de trabalho, uma vez que a comunicação mercadológica encontra-se num contexto de diluição dos limites entre comunicação interna e externa das organizações, exigência permanente de resultados mensuráveis e estruturação organizacional a partir de cadeias de valor horizontais, entre outras mudanças intensas e apontadas por diversos autores. Gracioso (2010), por exemplo, abriga a complexidade da comunicação atual sob a nomeação de Arenas da Comunicação com o Mercado, termo que abrange mega-shows de música; patrocínio de atletas ou clubes e grandes eventos esportivos; o universo da moda; grandes feiras; o mundo digital; o grande varejo; além da própria publicidade. Uma proposta inspirada nas ideias desenvolvidas pelo pensador francês Guy Debord (1967), que reconhece o espetáculo como o denominador comum da complexa configuração da comunicação contemporânea. Gracioso (2010) lembra ainda que novas arenas surgem a todo o momento, refletindo a evolução econômica e social. Fenômeno que pode ser também compreendido com as lentes das cadeias produtivas, que se sobrepõem e articulam em arranjos até então imprevisíveis; e das Indústrias Criativas, situadas no cruzamento das artes, cultura, negócios e tecnologia. Um contexto onde os trabalhadores são como pontos nodais (destituídos de conteúdo) numa rede em permanente mudança e precisam estar aptos a desempenhar inúmeras tarefas (SENNETT, 2006, p.168). Além disso, a questão está inserida, num escopo mais amplo, no entendimento da educação superior como espaço de reflexão e não apenas de formação profissional, como destaca Lima (2011, p.143), entre diversos autores, ao lembrar que "a formação profissional ligada a habilidades específicas não pode ser confundida com educação superior voltada para a educação formal e política dos estudantes". Ou seja, ao tentar "correr atrás" das práticas de mercado a universidade 


\section{Observistotório}

ISSN n² 2447-4266

Vol. 1, n 2, Setembro-dezembro. 2015

DOI: http://dx.doi.org/10.20873/uft.2447-4266.2015v1n2p174

perde a oportunidade de oferecer uma formação polivalente e capaz de responder às mudanças no ambiente da comunicação mercadológica, inserida no universo mais amplo de informação e comunicação.

\section{Criatividade coletiva e materialidade}

Tendo como ponto de partida as questões levantadas para justificar a proposta, passamos a apresentação do modelo teórico para o ensino e aprendizagem de criação publicitária. Distante da percepção da criatividade com um dom inato, que apenas poderia ser aperfeiçoado pela reflexão e prática, esta proposta fundamenta-se numa concepção de criatividade que opera o deslocamento de um pensar individualizado para uma percepção coletiva e social dos processos criativos. Tal concepção associa-se a assunção de responsabilidades, uma vez que, partindo-se do princípio de que o ato criativo é social e implica compromisso, não é possível tratá-lo sem falar de suas responsabilidades. Por outro lado associa-se ao fazer concreto, pois como lembra Ostrower (1987) não há criatividade abstrata, desligada de uma materialidade que the dê suporte e vida. A criatividade de um redator constrói-se a partir de um domínio das palavras e seus significados, das estruturas gramaticais, das figuras de linguagem. A criatividade de um pintor, por sua vez, está ancorada no conhecimento dos tipos de telas, tintas e pincéis. Da mesma forma podemos falar de administradores criativos, profissionais de mídias criativos, pesquisadores criativos e por aí afora.

A partir desse processo criativo coletivo e ancorado na materialidade destacamos esquematicamente a seguir as três dimensões que a nosso ver, potencializam o processo criativo, elevando-o ao que poderíamos chamar de uma criatividade ao cubo: Repertório operacionalizável, ligado à leitura das coisas e ao fazer concreto; Capacidade de combinação, competência desenvolvida por meio de observação, tentativa e erro; e Responsabilidades plurais. envolvendo questões sociais, culturais e criativas, entre outras. 


\section{Oesevisto}

ISSN n² 2447-4266

Vol. 1, n², Setembro-dezembro. 2015

DOI: http://dx.doi.org/10.20873/uft.2447-4266.2015v1n2p174

\section{Repertório operacionalizável}

A ampliação da bagagem cultural, pelo conhecimento de obras literárias e artísticas é condição amplamente conhecida para municiar o processo criativo. O que nos parece mais interessante, contudo, é centrar esforços na tentativa de tornar essa bagagem operacionalizável, exercitando nossa capacidade de combinar, de forma inusitada, o repertório de formas e conteúdos que adquirimos ao longo da vida. São, portanto, dois esforços, uma atitude aberta e curiosa que permita a "leitura das coisas"; e o exercício de combinações a partir do repertório adquirido.

O ler as coisas é observar. É uma observação geradora de combinações criativas. Nesse sentido, a publicidade parece encontrar alguns caminhos na crônica literária, que propõe uma atenção especial para com todas as coisas. Para Belinky,

As ideias vêm de muita vivência, muita leitura, muitos encontros - mas principalmente, do uso dos nossos "olhos de ver" e "ouvidos de escutar". Isto é da observação atenta e constante de tudo o que acontece com a gente e em volta da gente: em casa, em família, na escola, na rua, no ônibus, na fila do cinema, no supermercado - em todo e qualquer lugar... (BELINKY, 2002, p.9)

Esse conhecimento no caso de um redator publicitário se constrói, entre outros caminhos, pelo domínio de suas ferramentas de trabalho, pelo conhecimento de formas literárias, pela habilidade com as palavras. Como podemos ilustrar pelo prefácio redigido por Chico Buarque (2010) para o Dicionário Analógico da Língua Portuguesa, onde ele descreve o prazer em conhecer e dominar as palavras, matérias-primas do seu fazer criativo:

Pouco antes de morrer, meu pai me chamou ao escritório e me entregou um livro de capa preta que eu nunca havia visto. Era o dicionário analógico de Francisco Ferreira dos Santos Azevedo.(...) Era como se ele, cansado, me passasse um bastão que de alguma forma eu deveria levar adiante. E por um bom tempo aquele livro me ajudou no acabamento de romances e letras de canções, sem falar das horas em que eu o folheava à toa; (...) escarafunchar o dicionário analógico foi virando para mim um passatempo (desenfado, espairecimento, entretém, solaz, recreio, filistria). O resultado é que o livro, herdado já em estado precário, começou a se esfarelar nos meus dedos... 


\section{Obevisto}

ISSN n² 2447-4266

Vol. 1, n², Setembro-dezembro. 2015

DOI: http://dx.doi.org/10.20873/uft.2447-4266.2015v1n2p174

A ampliação do repertório associa-se também ao conceito de materialidade: o pensar específico sobre um fazer concreto, que leva em conta a matéria cultural com suas qualificações e compromissos que definem os limites do possível para cada indivíduo (OSTROWER, 1987, p.147). Aqui retomamos as ideias da autora, para quem cada materialidade abrange certas possibilidades e certas impossibilidades de ação que são limitadoras, mas também orientadoras, sugerindo novos caminhos para prosseguir um trabalho. A imaginação criativa vincula-se, portanto, à especificidade de uma matéria, que levanta hipóteses sobre configurações possíveis. Trata-se de um "pensar específico sobre um fazer concreto". Ostrower lembra ainda que as materialidades não são somente fatos físicos, mas também se colocam num plano simbólico, sendo que suas ordenações possíveis ensejam modos de comunicação. As propostas de materialidades específicas constituem as propostas de cada linguagem. Dessa forma, indagações à matéria constituem também formas de relacionamento afetivo e respeito pela essencialidade de um fenômeno. Uma proposta que encontra ressonância em Head (1986) e sua "educação nas coisas", para quem o talento artístico é uma questão de poesia (de poiesis, fazedor - captador de coisas reconhecíveis pela experiência), ou seja, de captar a realidade, captar coisas.

\section{Capacidade de combinação}

A partir do repertório adquirido, vários autores, empresas e profissionais desenvolveram, desde truques e táticas para o dia-a-dia, até teorias mais elaboradas para estimular a criatividade, que na sua maior parte focam a quebra de bloqueios e liberação do fluxo de idéias. Optamos por trabalhar na contramão dessas propostas, valendo-nos das ideias de Raymond Queneau (1920-1976) que achava pouco produtivo depender apenas da inspiração ou de mecanismos que criem situações inspiradoras e, em toda sua obra, privilegiou o trabalho sistemático, o esforço, a transpiração. Matemático, enciclopedista e escritor eclético, Queneau produziu várias obras com grande senso de humor e leveza, a partir da combinação quase 


\section{Obevisto}

ISSN n² 2447-4266

Vol. 1, n 2, Setembro-dezembro. 2015

DOI: http://dx.doi.org/10.20873/uft.2447-4266.2015v1n2p174

matemática de modelos, gêneros, estilos e regras. Estruturas que eram percebidas por ele não como elementos limitadores, mas como peças que, combinadas, podiam elevar a criatividade ao quadrado, ao cubo ou até a $14^{\circ}$ potência, como explicitou no livro Cent mille milliards de poèmes, sua "máquina" de fazer sonetos. Uma pequena obra que permite a qualquer um compor, à vontade, cem bilhões de sonetos. Composta por dez sonetos (14 versos), com as mesmas rimas impressas sobre páginas cortadas em tiras, permitindo que, após cada primeiro verso, o leitor tenha dez escolhas para o segundo e assim por diante, até atingir o número máximo de 1014 combinações.

Esse curioso autor integrou o movimento surrealista, onde, como descreve Heloísa Prieto (1999) no livro Quer ouvir uma história?, debateu a questão da criatividade com André Breton. Enquanto este associava o processo criativo ao rompimento das barreiras do inconsciente, Queneau acreditava que não devíamos ser escravizados pela inspiração (ou pela falta dela). Para ele um autor clássico que escreve segundo regras bem conhecidas é mais livre do que o poeta que escreve o que the passa pela cabeça e é escravo de regras que ignora. As divergências com Breton levaram ao rompimento com a trupe surrealista e Queneau passou a criticar duramente o movimento, combatendo a equivalência estabelecida entre inspiração, exploração do subconsciente e libertação, e valorizando uma obra lapidada com plena consciência das regras formais. Não prezava, contudo, a formas engessadas, como atesta sua batalha por um "neofrancês", que incorporasse a agilidade, inventividade e economia expressiva da linguagem oral ao francês falado. Transitava entre diferentes gêneros e estilos literários, inventando e sondando possibilidades e percebendo as estruturas como pontos de partida para renovar a criatividade e sacudir hábitos intelectuais. Seus livros típicos são construções únicas, como Exercícios de Estilo publicado pela primeira vez em 1948 e considerado por muitos como sua obra-prima. Nesses "exercícios", Queneau, a partir de história aparentemente banal, elabora uma série de 99 variações e deixa transparecer a força 


\section{Obevisto}

ISSN n² 2447-4266

Vol. 1, n², Setembro-dezembro. 2015

DOI: http://dx.doi.org/10.20873/uft.2447-4266.2015v1n2p174

e o potencial dos modelos, recriando a narrativa ao estilo filosófico, olfativo, telegráfico, matemático, na língua do pê, como um sonho, por meio de surpresas, e por aí afora.

No âmbito da publicidade, o vazio gerado pela falta de informações ou por um briefing muito aberto sinaliza como a criação pode ser auxiliada por restrições e direcionamentos capazes de delimitar o espaço (e o tempo) no qual o publicitário deve trabalhar. Com o propósito de explorar justamente o potencial inerente às restrições, foi criado em 1960, por Queneau e pelo matemático François Le Lionnais, o Oulipo Ouvroir de Littérature Potentielle (Ateliê de Literatura Potencial).

Ítalo Calvino, que foi integrante do Oulipo, sintetiza, no livro Por que ler os clássicos (1993) aspectos da filosofia de Queneau que definem a proposta do grupo. Na lógica da literatura potencial, a estrutura é liberdade. Cada exemplo de texto construído segundo regras precisas abre a multiplicidade "potencial" de todos os textos virtualmente passíveis de serem escritos e de todas as suas leituras virtuais. Um método onde o que conta é a qualidade, engenhosidade e elegância das regras e onde as obras são exemplos das potencialidades alcançáveis somente por meio de limitações escolhidas voluntariamente, opostas às limitações impostas pelo ambiente (linguísticas, culturais etc.).

Além da já citada "máquina de sonetos", que pode ser aplicada a menus de restaurante, receitas de cozinha, sambas-enredo e muitos outros tipos de texto (slogans, quem sabe?) e dos Exercícios de Estilo, cuja técnica consiste na redação de uma história banal, de poucas frases, reescrita várias vezes, pinçamos, como ilustração, duas "restrições", ou "contratos criativos", criados por Queneau, entre as mais de 80 disponíveis hoje no site da Oulipo (www.oulipo.net): a literatura "definicional" e a "transducção". A literatura "definicional" (Littérature définitionnelle), criada em 1966, consiste em, a partir de um determinado texto, substituir cada vocábulo significante (substantivo, adjetivo, verbo e advérbio) por uma das definições disponíveis em dicionários, repetindo a operação em relação ao texto 


\section{Obevisto}

ISSN n² 2447-4266

Vol. 1, n², Setembro-dezembro. 2015

DOI: http://dx.doi.org/10.20873/uft.2447-4266.2015v1n2p174

obtido sucessivas vezes. Tem como extensão, a literatura "semi-definicional" onde em vez das definições "clássicas", podem ser escolhidas ou criadas definições mais imprevisíveis; e variantes, como a escolha de dois enunciados os mais diferentes possíveis, que tratados, acabem formando um texto único. Ou seja, sempre que possível, ao término de uma série de transformações "definicionais" deve-se evoluir de um texto para qualquer outro. Já a "Transducção" (Transduction) propõe a substituição dos substantivos de um determinado texto por outros, provenientes de outro universo vocabular. Queneau, procedendo dessa forma, reconstruiu o artigo Os Fundamentos da Geometria, do matemático David Hilbert, substituindo as palavras "ponto", "reta" e "plano" por "palavras", "frases" e "parágrafos". Mais do que oferecer uma lista de exercícios, com regras por vezes complicadíssimas, as experiências do Oulipo indicam as inúmeras possibilidades advindas do conhecimento profundo e do desenvolvimento da capacidade de brincar com fórmulas cristalizadas e aparentemente esgotadas, como formas textuais simples, gêneros literários e manuais de roteiro. Uma atitude e organização mental que, como lembra Ítalo Calvino, não se adaptam às vias fáceis e nos parecem bastante adequadas ao universo da publicidade.

A estrutura é liberdade, produz o texto e ao mesmo tempo a possibilidade de todos os textos virtuais que podem substituí-lo. Essa é a idéia da multiplicidade "potencial" [...] O automatismo por meio do qual as regras do jogo geram a obra se contrapõe ao automatismo que apela para o acaso ou para o inconsciente, isto é, confia a obra a determinações não controláveis, às quais só resta obedecer. Em suma trata-se de opor uma limitação escolhida voluntariamente às limitações impostas pelo ambiente. (CALVINO, 1993. $\mathrm{p}$ 270)

Com Ostrower (1987, p.79-81) lembramos ainda que a forma pode ser compreendida como a estrutura das relações, como o modo por que as relações se ordenam e se configuram. Para ela, forma é estrutura e ordenação, e corresponde ao conteúdo significativo das coisas. A autora distingue ainda duas modalidades principais de ordenação, que nos parecem úteis para trabalhar a criatividade: ordenações de campo (acentua-se a unicidade de um acontecimento- fato concreto 


\section{Obevisto}

ISSN n² 2447-4266

Vol. 1, n², Setembro-dezembro. 2015

DOI: http://dx.doi.org/10.20873/uft.2447-4266.2015v1n2p174

e único em determinado momento) e ordenações de grupo (onde se generaliza e conceitua). Para ilustrar dá o exemplo de pães sobre a mesa, que podem ser ordenados com o enfoque da fome, sendo agrupado com outros alimentos, pratos e talheres e com o enfoque da contagem, reunido a outros pães.

\section{Responsabilidades plurais}

Para concluir, seguindo a proposta de ampliar a capacidade criativa a partir de restrições, acrescentamos mais uma obrigatoriedade. Para sermos "criativos ao cubo" (ou a outras potências mais altas), precisamos articular ao repertório ampliado de formas e conteúdos disponíveis e à capacidade de combinação obtida por meio do fazer concreto ligado a materialidades, uma reflexão cotidiana sobre as implicações do nosso trabalho em relação a todos aqueles que são retratados e atingidos pela publicidade. Aqui tratamos de responsabilidades plurais: sociais, culturais e criativas, entre outras.

Acreditamos, com Ostrower (1987) que tais responsabilidades não restringem a capacidade criativa, mas pelo contrário, impõem limites que delineiam o real sentido da liberdade de criar. Mais do que aceitar, é importante ter respeito e apreço pelos limites, uma vez que as balizas ou parâmetros são fundamentais para a criação. Além disso, criar implica aceitar a responsabilidade por aquilo que se cria. Não é possível, para seres conscientes e sociais, ficar isentos das implicações de suas opções e ações. Limites não são, portanto, áreas proibitivas, mas áreas indicativas e fontes inesgotáveis para a criação. Cabe a nós, como professores, estudantes e praticantes da publicidade, o desafio de escolher caminhos criativos capazes de obter impacto comunicacional e ao mesmo tempo sermos cuidadosos quanto aos valores que estão sendo veiculados. Assim como sermos corresponsáveis pela ampliação do repertório do público com a apresentação de manifestações culturais diversificadas, e pela diversificação saudável das formas de representar o outro, entre outras 


\section{Obevisto}

ISSN n² 2447-4266

Vol. 1, n 2, Setembro-dezembro. 2015

DOI: http://dx.doi.org/10.20873/uft.2447-4266.2015v1n2p174

responsabilidades. Pois, como nos ensina Ostrower (1987), esse tipo de compromisso é que torna uma prática efetivamente criativa.

Vale lembrar também que no que tange a educação superior acreditamos que, como afirma Hermann (2005, p.23-75) uma aproximação entre ética e estética pode ser muito produtiva. Uma vez que ao invés de ficar desorientada pela ausência de fundamentos normativos e racionalismos restritivos (associados ao declínio das éticas tradicionais, fundamentadas na razão), a educação pode renovar suas exigências éticas a partir da experiência estética, fazendo uso do seu caráter surpreendente e inovador. Essa autora lembra que o sujeito ético desejado pelo projeto pedagógico moderno, se constitui numa "pluralidade de experiências e numa abertura ao mundo e ao outro para os quais a experiência estética, enquanto um horizonte aberto, assume um sentido eminentemente formativo". A experiência estética traz o estranho, a inovação e a pluralidade que não podem desconsiderados no plano da ética. Voltando a Ostrower (1987, p.87) devemos ficar atentos ao valor da experiência sensível, assim como o caráter sensual do viver e unicidade da vida. A racionalização coloca o "conceito" num pedestal, mas reduz o conceituar a classificar e rotular. A autora não sugere com isso um ser humano menos intelectual, mas sim uma inteligência complementada em todos os momentos pela sensibilidade e maturidade emocional de cada pessoa.

\section{O modelo proposto: criativo ao cubo}

Retomando as três dimensões trabalhadas, temos a seguinte "equação", ou modelo teórico que visa contribuir com a aprendizagem e a prática da criação publicitária, envolvendo a construção de um repertório operacionalizável a partir da leitura das coisas e de uma aproximação respeitosa e afetiva em relação às materialidades que dão substância ao processo criativo (não há criatividade "abstrata"); a ampliação da capacidade combinatória a partir desse repertório (criamos a partir do que conhecemos e criamos melhor a partir do que conhecemos 


\section{Obevisto}

ISSN n² 2447-4266

Vol. 1, n², Setembro-dezembro. 2015

DOI: http://dx.doi.org/10.20873/uft.2447-4266.2015v1n2p174

bem), percebendo a criatividade como potencial inerente ao ser humano passível de ser realizado a partir do exercício constante; e a atenção às responsabilidades plurais envolvidas no processo criativo como ato social (responsabilidades que funcionam, a nosso ver, como limites que dão forma e potencializam ainda mais a criatividade).

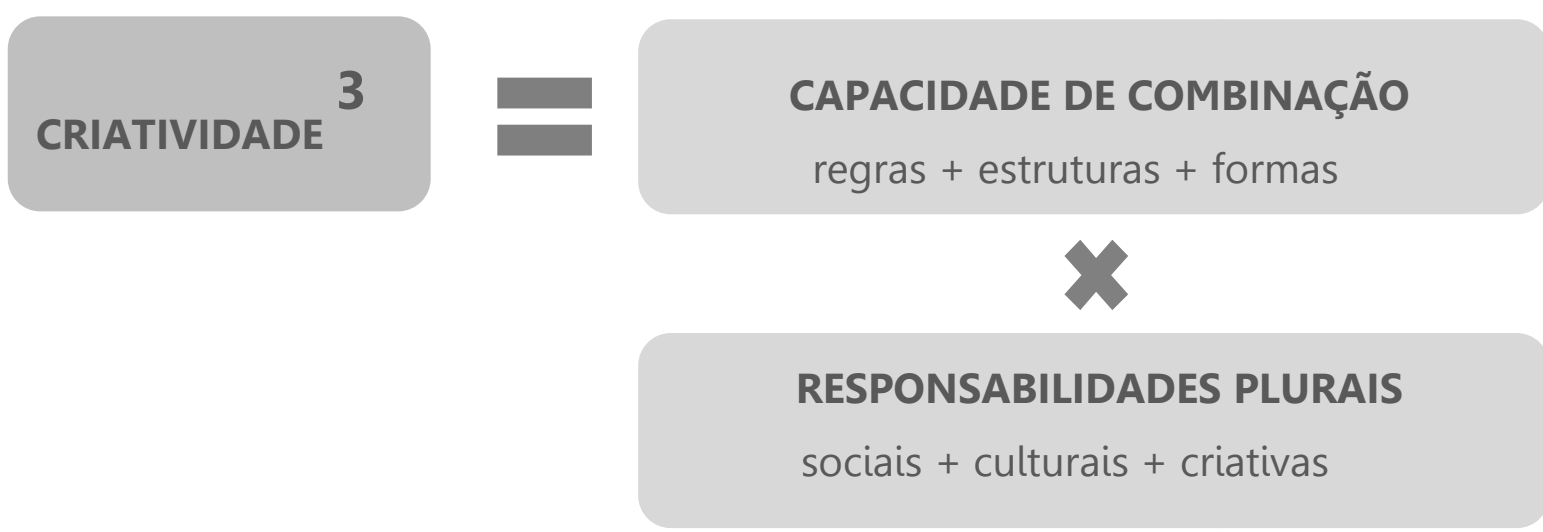

Ou se fossemos pensar de forma tridimensional, seriam três os vetores capazes de ampliar do espaço e as possibilidades criativas do estudante e futuro cidadão e profissional. O repertório/leitura das coisas e a capacidade de combinação seriam responsáveis pela ampliação bidimensional das possibilidades e a atenção à dimensão social da comunicação e suas responsabilidades plurais seria responsável por conferir a estatura ética do estudante/cidadão/profissional. 


\section{Qrevisto \\ Qbservatório \\ ISSN n² 2447-4266 \\ Vol. 1, n², Setembro-dezembro. 2015 \\ DOI: http://dx.doi.org/10.20873/uft.2447-4266.2015v1n2p174}

\section{Considerações finais: experiência, publicidade e arte}

O modelo aqui apresentado baseia-se em grande parte numa atitude experimental como caminho para cultivar a criatividade e valorizar o ambiente educacional no sentido de torná-lo favorável a descoberta. Vale destacar, contudo, que nem toda a experiência é educativa. Dewey (2010, p26-28) ao argumentar pela necessidade de uma teoria da experiência afirma que algumas experiências são, inversamente, deseducativas. Para esse autor qualquer experiência que tenha o efeito de dificultar o preparo e a abertura para novas experiências é deseducativa. Uma experiência pode, por exemplo, produzir indiferença e insensibilidade ao aumentar a destreza de uma habilidade automática e habituar o indivíduo a certas rotinas, limitando a possibilidade de novas experiências. Por outro lado uma experiência excessivamente divertida pode contribuir para uma atitude negligente. Ao avaliarmos a qualidade da experiência devemos levar em conta dois aspectos fundamentais: o fato de ser agradável ou desagradável no momento em que ocorre e sua capacidade de influenciar experiências posteriores (e talvez ressignificar experiências anteriores, podemos acrescentar).

Seguindo esse raciocínio, observamos que a experiência estética por meio de uma aproximação da publicidade com a arte pode ser extremamente produtiva, tanto no reconhecimento do papel social da atividade e suas responsabilidades, quanto no enriquecimento do processo criativo. Nesse sentido, Piratininga (1994, p.73) lembra que a publicidade entrelaça formas tradicionais de arte com as que the são características e prepara novas condições de existência dos consumidores que a recebem e que, por ela, tem alterada sua visão de mundo, suas expectativas e seu comportamento. E acrescenta que a construção da base estética eficiente e eficaz de cada mensagem a publicidade dispõe de recursos artísticos. Diante disso esse autor 


\section{Obevisto}

ISSN n² 2447-4266

Vol. 1, n², Setembro-dezembro. 2015

DOI: http://dx.doi.org/10.20873/uft.2447-4266.2015v1n2p174

propõe uma aproximação entre o ensino da publicidade e da arte, tendo como fundamento a apresentação e prática de noções básicas de técnica e materiais, o acompanhamento do estudante em suas tentativas, ajudando-o a desvelar sua própria sensibilidade e a cobrança de uma maciça exposição ao Saber e ao Belo (PIRATININGA, 1994: p.87-88).

Tosin (2006) reitera e desdobra essa posição ao propor uma análise da publicidade no contexto histórico e crítico da arte, fornecendo subsídios para pensar a complexidade das manifestações culturais mediadas pelos meios de comunicação e caracterizadas pela "convergência de linguagens e fatores expressivos de naturezas diversas". Duarte Jr. (2001), por sua vez, inclui a relação da arte com a ética e o raciocínio ao ponderar que se cabe à arte o papel de instrumento para a educação da sensibilidade e descoberta a de nova forma de significação que não a conceitual, parece necessário que sua inserção em processos educacionais ocorra conjuntamente ao desenvolvimento de valores éticos e raciocínio lógico, combinando sensibilidade e racionalidade. Realiza-se dessa forma, a nosso ver, a satisfação do potencial criativo inerente ao homem, que se constitui em uma de suas necessidades fundamentais. Pois a criatividade representa a potencialidade do ser único e sua criação é a realização dessas potencialidades no âmbito de determinada cultura. (OSTROWER, 1987, p.5).

Resta saber de que forma isso será feito. A aproximação conceitual entre arte e publicidade, passando pela noção de compromisso, é o caminho que este texto, fazendo eco a vários outros, sugere. Um caminho que busca tornar a publicidade menos tecnicista e mais humanizada, com uma perspectiva esperançosa, mas não ingênua, do que a publicidade pode ser ao privilegiar uma postura mais crítica, assumindo suas responsabilidades sociais, culturais e educativas. 


\section{Orevisto}

ISSN n² 2447-4266

Vol. 1, n², Setembro-dezembro. 2015

DOI: http://dx.doi.org/10.20873/uft.2447-4266.2015v1n2p174

E também, como lembra Tavares (2011) o ensino de publicidade pode e deve ser mais futurista e sonhador do que o mercado e regido por uma "racionalidade reflexiva", contribuindo, quem sabe, para a realização de todo potencial da atividade enquanto ação cultural, vislumbrado por Toscani.

A publicidade poderia tornar-se a parte lúdica, fantasista ou provocante da imprensa. Poderia explorar todos os domínios da criatividade e do imaginário, do documentário e da reportagem, da ironia e da provocação. Poderia oferecer informações sobre todos os assuntos, servir grandes causas humanistas, revelar artistas, popularizar grandes descobertas, educar o público, ser útil, estar na vanguarda. Que estopim! (TOSCANI, 1996, p. 4647).

Para finalizar lembramos que a denominação "modelo teórico" talvez seja muito ambiciosa para o esquema aqui proposto. Optamos, contudo, por nomeá-lo dessa forma mesmo no estado preliminar que se encontra para indicar a intenção de aperfeiçoá-lo ou reconstruí-lo a partir do diálogo com pesquisadores e praticantes dos campos da comunicação e da educação.

\section{Referências}

BELINKY, T. Acontecências. Coleção Vida à vista. Belo Horizonte: Ed. Dimensão, 2002.

CALVINO, I. Por que ler os clássicos? São Paulo: Cia. das Letras, 1993, p. 254272.

DEWEY, J. Experiência e educação. Petrópolis, RJ: Vozes, 2010.

DUARTE JR., J. O Sentido dos sentidos: a educação (do) sensível. $5^{a}$ edição. Curitiba, PR: Criar Edições, 2001.

HANSEN, F. O ensino de criação publicitária e a sua relação com o mercado publicitário. Trabalho apresentado no GP Publicidade e Propaganda do XI 


\section{Obevisto}

ISSN n²447-4266

Vol. 1, n², Setembro-dezembro. 2015

DOI: http://dx.doi.org/10.20873/uft.2447-4266.2015v1n2p174

Encontro dos Grupos de Pesquisa em Comunicação, evento componente do XXXIV Congresso Brasileiro de Ciências da Comunicação, Recife, 2011.

As formações imaginárias e seus efeitos de sentido no ensino e na aprendizagem de criação publicitária. Educ. Pesqui., São Paulo , v. 39, n. 2, jun. 2013 . Disponível em <http://dx.doi.org/10.1590/S1517-97022013000200012 >. Acesso em 19 jul. 2014.

HERMANN, N. Ética e estética: a relação quase esquecida. Porto Alegre: EDIPUCRS, 2005.

HOLLANDA, F. B. Os dicionários de meu pai. In: AZEVEDO, F. F.S. Dicionário analógico da língua portuguesa. Rio de Janeiro: Lexikon, 2010, p. v.

LIMA, M. C. A (In) competência Diplomada. In: CASAQUI, V.; LIMA, M. C.; RIEGEL, V. (orgs.). Trabalho em publicidade e propaganda: história, formação profissional, comunicação e imaginário. São Paulo: Atlas, 2011.

OSTROWER, F. Criatividade e processos de criação. $18^{\circ}$ edição. Petrópolis, RJ: Vozes, 1987.

PIRATININGA, L.C. Publicidade: arte ou artifício? São Paulo: T. A. Queiroz, 1994.

PRIETO, H. Quer ouvir uma história? Lendas e mitos no mundo da criança. São Paulo: Editora Angra, 1999.

READ, H. A redenção do robô. São Paulo: Summus, 1986.

SENNETT, R. A cultura do novo capitalismo. Rio de Janeiro: Record, 2006.

TAVARES, D. Racionalização no ensino da publicidade digital. Trabalho apresentado no GP Publicidade e Propaganda do XI Encontro dos Grupos de Pesquisa em Comunicação, evento componente do XXXIV Congresso Brasileiro de Ciências da Comunicação, Recife, 2011.

TOSCANI, O. A publicidade é um cadáver que nos sorri. 3a ed. Rio de Janeiro: Ediouro, 1999. 


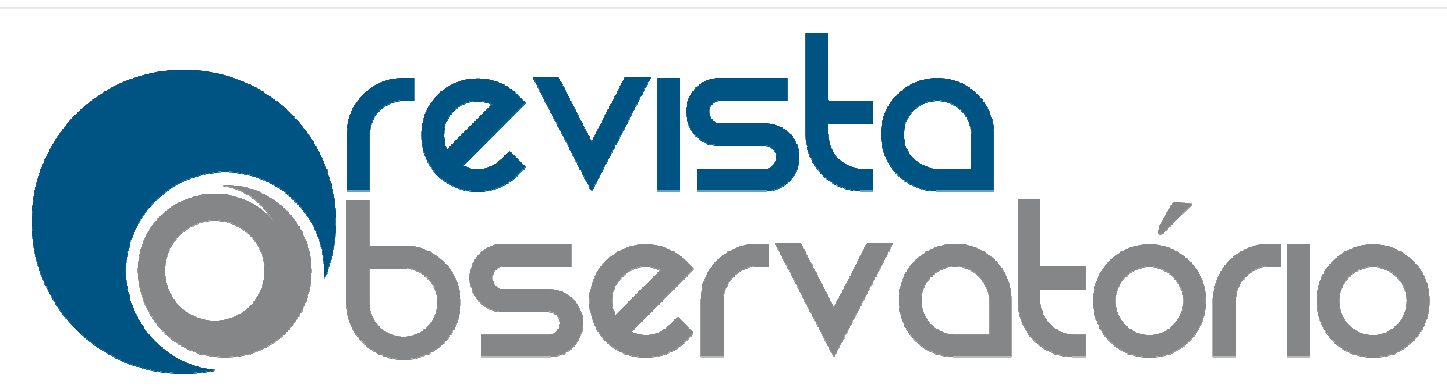

ISSN n² 2447-4266

Vol. 1, n², Setembro-dezembro. 2015

DOI: http://dx.doi.org/10.20873/uft.2447-4266.2015v1n2p174

TOSIN, G. Publicidade e Arte: Perspectivas para o Estudo de um Sincretismo Contemporâneo. Trabalho apresentado no NP Publicidade e Propaganda do VI Encontro dos Grupos de Pesquisa em Comunicação, evento componente do XXIX Congresso Brasileiro de Ciências da Comunicação, Brasília, 2006.

Acesse esse e outros artigos da Revista Observatório em:

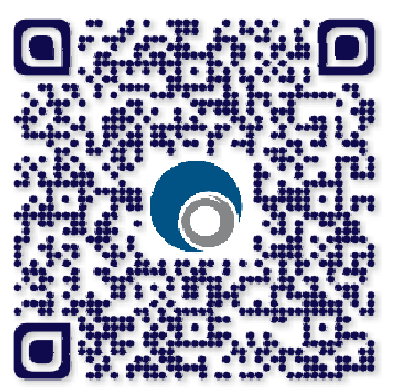

